\title{
Ecology and evolution of extravagant feather ornaments
}

\author{
J. J. CUERVO* \& A. P. MØLLER† \\ *Estación Biológica de Doñana, Consejo Superior de Investigaciones Cientificas, Avenida María Luisa s/n, Pabellón del Perú, E-41013 Sevilla, Spain \\ $\uparrow$ Laboratoire d'Ecologie, CNRS URA 258, Université Pierre et Marie Curie, Bât. A, 7ème étage, 7, quai St. Bernard, F-75252 Paris Cedex 5, France
}

\section{Keywords:}

feathers;

mate choice;

mating system;

parental care;

sexual selection.

\begin{abstract}
The ancestral conditions that permit the evolution of extravagant secondary sexual characters are of considerable theoretical and empirical interest because they allow identification of necessary ecological conditions, but also allow empirical tests of models of female mate preferences. We investigated the ancestral and derived state of a range of ecological and evolutionary variables that might have been implicated in the evolution of secondary sexual characters. Extravagant feather ornaments have evolved independently at least 70 times in birds, and the context of these evolutionary events was investigated statistically. The acquisition of feather ornaments was significantly associated with a change in social mating system from monogamy to polygyny or lekking. This association is consistent with the Fisherian mechanism of sexual selection. However, very often also the acquisition of feather ornaments occurred without change in mating system. Therefore, ornamentation can develop for reasons other than polygyny. We did not find any indication of male parental care, kind of food, foraging mode, coloniality, nest site, migration or body mass being significantly associated with a change in the state of ornamentation.
\end{abstract}

\section{Introduction}

Despite only a fraction of all organisms having evolved extravagant secondary sexual characters, these have played an important conceptual, theoretical and empirical role in evolutionary biology (Darwin, 1871; Cronin, 1991; Andersson, 1994). Secondary sexual characters such as the antlers of deer and the train of the blue peacock Pavo cristatus are presumed to have arisen and be maintained as a result of directional sexual selection. Individuals with more extreme character values are expected to benefit in terms of male-male competition and/or female choice, respectively. An evolutionary understanding of sexual selection not only requires knowledge of the maintenance, but also of the origin of the characters in question. Almost the entire current surge in interest of sexual selection has been focused on the maintenance of secondary sexual characters based on observational and

Correspondence: José Javier Cuervo, Estación Biológica de Doñana, Consejo Superior de Investigaciones Científicas, Avenida María Luisa s/n, Pabellón del Perú, E-41013 Sevilla, Spain.

Tel: +34 954232340; fax: +34 954621125; e-mail: jcuervo@cica.es experimental studies of male-male competition and female choice (Andersson, 1994; Møller, 1994). The origin of extravagant ornamentation is, however, equally interesting for a complete understanding of sexual selection. Andersson (1994) in his recent review of sexual selection listed only five comparative studies of sexual ornamentation (Clutton-Brock et al., 1977, 1980; Höglund, 1989; Møller \& Pomiankowski, 1993; Höglund \& Sillén-Tullberg, 1994), and none of these addressed the question of the ecological conditions being associated with the evolution of extravagant ornamentation.

Models of sexual selection can be classified in different ways (Andersson, 1994; Møller, 1994), but here we adopt a classification based on the kinds of benefits acquired by individuals of the choosy sex, usually females. Fitness benefits obtained by choosy individuals are either direct or indirect. Direct fitness benefits can be obtained in terms of parental care, a high fertilizing ability, absence of contagious parasites, territory quality, nuptial gifts or other kinds of resources (reviews in Andersson, 1994; Møller, 1994). Indirect fitness benefits are either so-called good genes that enhance the viability of offspring (Zahavi, 1975, 1977; Hamilton \& Zuk, 1982; Andersson, 
1986; Heywood, 1989; Iwasa et al., 1991; Folstad \& Karter, 1992) or arbitrary attractiveness genes that increase the mating success of sons (Fisher, 1930; Lande, 1981; Pomiankowski et al., 1991). These different kinds of models make certain assumptions or predictions concerning the conditions that are particularly likely to precede the evolution of extravagant secondary sexual characters. Models of direct fitness benefits assume that features of direct benefits provided by individuals of the chosen sex are likely to be present before and particularly after the evolution of the secondary sexual character. Models of viability indicators do not make any predictions concerning resources provided by males, although one might predict that costly activities would be more likely to render signals reliable quality-indicators. Models of pure attractiveness predict that secondary sexual characters would be particularly suitable as female attractants in socially polygynous and particularly in lekking mating systems, although the mechanism might work, albeit in a weaker form, in socially monogamous mating systems.

Currently, we have only got the slightest knowledge of the ecological conditions that are associated with a change in state of extravagant ornamentation. Here we report on a comparative study of the ecological conditions associated with the evolution of a particular kind of secondary sexual characters: extravagant feather ornaments in birds, that is to say, feathers elongated in an exaggerated way, mainly in one of the sexes (generally males), as those of a peacock's train, a pheasant's tail and various feather traits in birds of paradise. These characters have played an important role in our understanding of sexual selection from the initial writings of Charles Darwin (1871) to more recent experimental studies (e.g. Andersson, 1982; Møller, 1988, 1992; Jones \& Hunter, 1993). There is ample observational and experimental evidence for extravagant feather ornaments being involved in female choice (Andersson, 1982, 1992; Møller, 1988, 1992, 1994; Barnard, 1990; Petrie et al., 1991; Smith et al., 1991; Evans \& Hatchwell, 1992; Saino et al., 1997d), while the same studies provide no or very little evidence for an effect on male-male competition. Feather ornaments are therefore primarily considered to be involved in female choice throughout this paper. They represent a suitable category of secondary sexual characters for study because they are easy to identify, they have evolved independently a very large number of times, and the ecological variables of interest are relatively well known in birds in general. The phylogenetic relationships of birds are also relatively well known allowing for proper analyses of the character transitions.

\section{Methods}

\section{Definition of feather ornaments}

We have identified independent evolutionary events of feather ornamentation in all extant birds. Sexual size dimorphism was considered either with or without complete sex limitation. We excluded cases of extravagant feather characters in both sexes when there was no sexual size dimorphism, even though mutual sexual selection may account for such exaggerated monomorphism (Jones \& Hunter, 1993). For the time being we assume that extravagant sexually size dimorphic traits are associated with sexual selection, as demonstrated by numerous observational and experimental studies (see Introduction). Sexual size monomorphism was not the subject of the present study. Furthermore, we have not considered either feather colours or naked skin patches in the present study.

Sexually size dimorphic traits were considered to qualify as secondary sexual characters if there was a sex difference in their size of at least $5 \%$ because previous studies have considered this cut-off point for dimorphism (Höglund, 1989; Oakes, 1992; Höglund \& Sillén-Tullberg, 1994). Species investigated were recorded from extensive searches of the literature and major European museum collections (see Acknowledgments). If we suspected that a species might be sexually size dimorphic in a feather character, we investigated this by measuring 10 males and 10 females of the species in question. A total of 82 such cases resulted in 12 being considered to be sexually size monomorphic, according to the criterion stated above, and the rest being sexually size dimorphic. A few bird species could not be included in our data set, or even classified as sexually size dimorphic or monomorphic, owing to a shortage of specimens in the museum collections visited. Although the list of sexually size dimorphic species is the largest so far, we cannot exclude the possibility that we have missed a few cases of slight sexual size dimorphism. The degree of dimorphism (( (male size - female size)/(female size) $) \times 100$ ) among species included in the present study ranged from $5 \%$ to $450.9 \%$ in species with partial sex limitation of ornament expression, with a mean value of $68.4 \%$ ( $\mathrm{SE}=13.4, n=49$ species). Moreover, ornament dimorphism was not due to a general difference in body size between sexes, because in the 41 species with males having longer tarsus than females, ornament dimorphism (as defined above) was on average 33.9 times larger than tarsus dimorphism $(\mathrm{SE}=8.0)$, and always more than 1.5 times larger. Species with a feather character only being expressed in males were all included in the study.

\section{Phylogenetic information}

We searched for phylogenetic information on the relationships between extant birds, but were forced to rely on taxonomic information in a number of cases. To this end we have used two different taxonomies: that of Sibley \& Ahlquist (1990) based on DNA-DNA hybridization and that of Howard \& Moore (1991) based on classical taxonomical information. Sibley and Ahlquist 
have been criticized for their methods (e.g. Krajewski, 1991; O'Hara, 1991; Raikow, 1991) and many recent phylogenies using sequence data differ from theirs (see Mindell, 1997). However, they have also been supported by other studies (Harshman, 1994; Mooers \& Cotgreave, 1994; Sibley, 1994; Bleiweiss et al., 1995). Therefore, we assessed the reliability of the analyses based on Sibley and Ahlquist by using independent phylogenetic information for the families Anatidae, Hirundinidae, Phasianidae, Ptilorhynchidae and Trochilidae (phylogenies in Livezey, 1986; Randi et al., 1991; Kusmierski et al., 1993; Sheldon \& Winkler, 1993; Bleiweiss et al., 1994). The supplementary phylogenies identified three cases of independent evolutionary events that were not identified using the phylogeny by Sibley and Ahlquist, and no cases identified by Sibley and Ahlquist that were unsupported by the alternative phylogenies. Hence, by relying on Sibley \& Ahlquist (1990) we have used a conservative estimate of the number of evolutionary events. Our method of choosing independent ornamentation events is likely to be conservative because the intrafamiliar phylogenetic relationships are unknown for many families with many ornamented species.

Feather ornamentation has evolved a large number of times. If no other phylogenetic information was available, we assumed that there was only a single evolutionary event in each family. If ornaments appeared in subfamilies or tribes that were phylogenetically separated, these were considered to be independent evolutionary events. If more than one trait had become exaggerated in a family, we considered this to represent a number of independent evolutionary events equalling the number of exaggerated traits. If, for example, a long tail was found in some species of a family and long crest feathers were found in other species, these occurrences were tallied as two independent evolutionary events of feather ornamentation, since these traits were obviously developmentally and morphologically independent.

Ornamented species were picked with respect to abundance if more than one choice was possible with the more abundant species being preferred owing to more ecological information being available for abundant species. We do not believe that latitudinal bias has been introduced in our sample as a result of the method of choice, since tropical species are also very well represented in the European museums visited, especially in the British Museum (Natural History), Tring, UK, where most specimens were measured. Actually, $80 \%$ of the ornamented species included in this study have all or part of their breeding range within the tropics. For pairwise comparisons, we randomly chose a nonornamented species within the same genus, if possible, or otherwise within the same subfamily. Our pairs of species were not sister taxa in the normal sense of the word, since in many cases the nonornamented species was not necessarily the closest relative. However, this does not change the interpretation of the results.

\section{Ecological variables}

Mating system

Species were classified as (1) socially monogamous if a male and a female associated for reproduction, (2) polygynous if at least $5 \%$ of the males in one population was associated with more than a single female for reproduction, (3) polyandrous if at least $5 \%$ of the females was associated with more than a single male for reproduction and (4) lekking if males aggregated at communal display grounds where females arrived to make their mate choice.

\section{Male parental care}

Male expenditure of reproductive effort on nest building, incubation and offspring provisioning was determined. Too little information was available for courtship feeding to allow this variable to be included. Species were classified as having no or some male contribution for each of the three categories. A more fine-scaled classification was impossible owing to lack of quantitative information for many species.

\section{Food}

Specific kinds of food may render extravagant ornaments less costly, if superabundant and predictable, and thereby reduce the costs of ornamentation. Other kinds of food may be difficult to obtain and constrain the evolution of ornamentation. We classified species as frugivorous if they mainly ate fruit, and consumers of animal food if they subsisted on invertebrates or vertebrates. The rest of the species were lumped together in a single category.

\section{Foraging mode}

Birds differ in their foraging modes and a number of different classifications are possible. Since our emphasis was on the consequences of costly behaviour for the likelihood of evolution of extravagant ornaments, we attempted to obtain estimates of these modes while lumping the rest. Aerial foragers obtain all their food from pursuing food (usually invertebrates) in flight. Divers pursue food while diving.

\section{Coloniality}

Social organization was classified as either colonial or solitary depending on whether nests were closely aggregated or dispersed.

\section{Nest site}

Bird species were classified as hole nesters or open nesters depending on whether they used holes or open sites for their nests.

\section{Migration}

Bird species were classified as migrants, partial migrants or residents depending on whether there was no overlap, 
some overlap or complete overlap between breeding and nonbreeding ranges due to seasonal movements.

\section{Body mass}

This was the average body mass for males and females.

The entire data set is listed in the Appendix. Information concerning the ecological variables of the bird species considered in this study was obtained from an extensive survey of the literature and from correspondence with scientists. The sources of information will be supplied to the readers upon request.

\section{Comparative and statistical methods}

We have used in this study a comparative method that control for similarities among species due to common ancestry. The pairwise comparative method contrasts the state of ecological variables of interest in closely related species differing in their degree of feather ornamentation (Felsenstein, 1985; Birkhead et al., 1987; Møller \& Birkhead, 1992). For simplicity and methodological rigour we have employed a pairwise comparative approach to our questions by making comparisons between species with feather ornaments and a closely related relative lacking feather ornaments. When the independent evolutionary events of extravagant feather ornamentation have been identified, pairwise statistical tests can be made with respect to the independent variable (for example, the social mating system). A common pattern of change is consistent with an evolutionary association between two variables of interest. The pairwise comparative method has the additional strength that potentially confounding variables will be controlled automatically because pairs of closely related species generally have a similar anatomy, physiology and ecology due to their common evolutionary past (Møller \& Birkhead, 1992). These tests were usually performed using nonparametric statistics for paired comparisons (Wilcoxon matched-pairs signed-ranks test) because all variables investigated (except body mass) were nominal or ordinal.

Statistical tests were performed according to Sokal $\delta$ Rohlf (1995) and Siegel \& Castellan (1988). All tests are two-tailed and the level of significance $5 \%$.

\section{Results}

\section{Social mating system}

High degrees of polygyny have since the days of Darwin been presumed to be associated with extravagant feather ornamentation (Darwin, 1871; Møller \& Pomiankowski, 1993), although this assumption has not been generally supported by comparative analyses (Höglund, 1989; Höglund \& Sillén-Tullberg, 1994).

We were able to identify the mating system for 65 pairwise comparisons. There was a change in mating system from a lower to a higher degree of mating skew being associated with acquisition of a feather ornament in 17 cases, while there were no changes in the opposite direction (Appendix; sign test, $P<0.001$ ). This change was also significant in a pairwise comparison (Wilcoxon matched-pairs signed-ranks test, $z=-3.74, P=0.0002$ ). Hence, the acquisition of extravagant feather ornamentation was indeed associated with a change in mating system from a lower to a higher degree of polygyny.

\section{Male parental care}

Male parental care has been invoked to be associated with the evolution of secondary sexual characters because males generally play a less important role in parental duties in species with more skewed mating success (Darwin, 1871; Orians, 1969). However, this prediction has never been tested.

Male parental care could only be classified as present or absent, and with this crude classification there was no evidence of a change in ornamentation being consistently associated with a change in male parental care. Most pairs of taxa showed no change at all in male care, and changes were not consistent among pairs with a change in the state of parental care (nest building: five pairs, two with an increase and three with a decrease; incubation: seven pairs, five with an increase and two with a decrease; offspring provisioning: six pairs, four with an increase and two with a decrease). These differences were not statistically significant (Wilcoxon matched-pairs signed-ranks tests, $z<1.13, P>0.26)$.

\section{Food and foraging mode}

Various kinds of food and foraging modes have been presumed to be associated with mating system and sexual ornamentation (e.g. frugivory and lekking in birds of paradise (Beehler \& Pruett-Jones, 1983)). However, we found no evidence for changes in character state of food or foraging mode being consistently associated with changes in ornamentation, although this conclusion was based on a small number of changes between sister taxa (Wilcoxon matched-pairs signed-ranks test; food: $z=-0.83$, NS; foraging mode: $z=0$, NS).

\section{Sociality}

Coloniality has traditionally been assumed to be associated with a spatially and temporally unpredictable food source (Lack, 1968), and extravagant ornamentation would therefore be particularly costly in a species with a colonial lifestyle. Coloniality is widespread among birds and has arisen independently many times.

There were very few cases where the state of sociality had changed within pairs of taxa, and there was no consistent change in ornamentation associated with acquisition of a colonial state of life (ornamentation 
arose with a change from solitary to colonial breeding in four cases and with a change from colonial to solitary breeding in four cases, Wilcoxon matched-pairs signedranks test, $z=0$, NS).

\section{Nest site}

Feather ornamentation was not significantly related to nest site when comparing sister taxa. Only three pairs showed a change in nest site during the transition from nonornamentation to ornamentation, and all were associated with a change from hole to open nesting (Wilcoxon matched-pairs signed-ranks test, $z=1.73$, $P=0.08)$.

\section{Migration}

Migration is an energetically very costly activity that is widespread among birds. Extravagant ornamentation might therefore be predicted to be less likely to arise in association with costly migration because the costly activity would simply be prohibitive for the evolution of extravagant ornamentation.

There were relatively few cases of the state of migratory habits changing within pairs of taxa. The analysis showed no significant differences, with ornamentation being associated with a change to a higher level of migration in 11 cases and to a lower level of migration in six cases (Wilcoxon matched-pairs signed-ranks test, $z=-1.03$, NS).

\section{Body mass}

Male mass was slightly larger in ornamented than in nonornamented taxa but the difference was not significant (mass of ornamented species (mean (SE)): $437 \mathrm{~g}$ (173), $n=68$; mass of nonornamented species: $236 \mathrm{~g}$ (79), $n=62$; paired $t$-test based on $\log _{10}$-transformed data, $t=1.56$, d.f. $=59, P=0.12$ ).

There was even less evidence of a difference in female body mass between ornamented and nonornamented species (mass of ornamented species (mean (SE)): $312 \mathrm{~g}$ (92), $n=58$; mass of nonornamented species: $203 \mathrm{~g}$ (55), $n=52$; paired $t$-test based on $\log _{10}$-transformed data, $t=1.35$, d.f. $=45, P=0.19$ ).

\section{Discussion}

The comparative analyses of the evolution of extravagant feather ornaments revealed that only the effect of mating system on ornamentation was significant. Extravagant feather ornaments were more likely to evolve in association with a change in the mating system from less to more skewed social mating success. This result is consistent with the initial observations of Darwin (1871) that secondary sexual characters appear to be more common and exaggerated in polygynous birds. There are a number of different explanations for this observation. First, the Fisherian mechanism of coevolving arbitrary male traits and female preferences is more important in mating systems with a greater skew in mating success (Fisher, 1930; Lande, 1981; Pomiankowski et al., 1991). Second, polygynous and particularly lekking bird species generally provide less male parental care than males of monogamous species (Lack, 1968), and the reduced role of males in reproduction allows a larger fraction of reproductive resources being allocated to mating effort and ornamentation. The reduced importance of male parental care also renders extravagant ornamentation energetically less costly, and a larger proportion of resources can therefore be allocated to ornamentation. Our results, however, did not demonstrate any significant relationship between decrease of male parental care and feather ornamentation.

Despite the key finding of ornamentation being associated with a change towards polygyny or lekking, it is important to emphasize that in 48 out of 65 cases, no change in mating system occurred with a change in ornamentation. This result can be interpreted in two ways. First, skew in male mating success can be extreme even in socially monogamous species because extra-pair paternity can result in a considerable increase in the variance in male mating success (Kirkpatrick et al., 1990; Møller, 1998). A change in the variance in male mating success within a monogamous clade may therefore result in the evolution of extravagant ornamentation. Second, while particular ecological conditions may interfere with the evolution of extravagant ornamentation, this does not necessarily imply that such an evolutionary change will not happen. For example, while a particular mating system may not be associated with the acquisition of ornaments, other ecological conditions may permit the evolution of ornamentation.

Ornaments are particularly costly to produce and maintain if they comprise feathers. Feathers consist of costly biochemicals and their mere presence imposes flight costs on their bearers. There is currently considerable observational and experimental evidence for the costs of feather ornamentation among birds. For example, current ornamentation is traded against future ornamentation (Møller, 1989), males incur a survival cost from their ornamentation (Møller \& de Lope, 1994; Saino et al., 1997a), ornamental feathers result in a foraging cost (Møller, 1989; Evans \& Thomas, 1992; Møller et al., 1995), ornamental feathers give rise to a predation cost (Møller \& Nielsen, 1997), and their presence gives rise to physiological costs (Saino et al., 1997b, c) and impaired immune function (Saino \& Møller, 1996).

Two scenarios are possible for the link between the costs of ornamentation and ornament evolution. First, ornaments are predicted to evolve in ecological contexts where there are permissible amounts of energy available for ornament production and maintenance. Therefore, 
they are only predicted to evolve in contexts where there is a change in state from more to less costly activities such as from a higher to a lower state of male parental care, from a more to a less costly mode of foraging, or from a less to a more predictable food source. Second, they are particularly likely to evolve in contexts where they reveal the phenotypic quality of their bearers from the very beginning (Fisher, 1930; Zahavi, 1975; Møller, 1994). Such a situation will provide choosy females with a considerable initial mating advantage because the ornament reliably reveals male quality, and the mate preference for more extremely ornamented males will therefore rapidly increase in frequency. These two not necessarily mutually exclusive ideas can be investigated using the ecological context of extravagant feather ornamentation. However, we found no indication for ornaments being more or less likely to evolve with a particular change in the cost of male activities.

Several previous studies have shown that changes in female traits, instead of changes in male traits, could be the origin of sexual dimorphism (dichromatism) in birds (Björklund, 1991; Irwin, 1994; Martin \& Badyaev, 1996; Burns, 1998). These changes in female coloration have been interpreted as responses to social selection or nest predation. Although some of the variables included in our studies were specifically male orientated (e.g. male parental care), some others could be affecting males and females in a similar way (e.g. food, coloniality, migration) or even affect females to a larger extent (e.g. nest site). However, we found no significant relationship between these variables and the presence of sexual dimorphism. Only mating system was significantly related to sexual size dimorphism of ornaments, which seems to emphasize the importance of sexual selection on the evolution of ornamentation. However, the relationship between mating system and sexual dimorphism is not as clear-cut, since some studies have found a significant relationship between the two variables (Scott 8 CluttonBrock, 1989; Oakes, 1992; Møller \& Birkhead, 1994), while others have not (Møller, 1986; Höglund, 1989; Höglund \& Sillén-Tullberg, 1994).

Sexual monomorphism may have been the ancestral state in birds (Temrin \& Sillén-Tullberg, 1994). The evolutionary transition from absence to presence of extravagant feather ornaments was often associated with a change in social mating system from monogamy to polygyny or lekking, but very often this transition occurred without change in mating system. Thus, ornamentation can develop for reasons other than polygyny.

\section{Acknowledgments}

We thank M. R. Evans, C. B. Frith and S. Pruett-Jones for kindly providing unpublished data. We are grateful to the curators of the bird collections in Alexander Koenig Museum, Bonn, Germany; British Museum (Natural History), Tring, UK; Doñana Biological Station, Seville,
Spain; Natural History Museum, Stockholm, Sweden; and Zoological Museum, Copenhagen, Denmark, for access to specimens. J.J.C. was supported by a postdoctoral grant from the European Union (Human Capital and Mobility Program) and by Spanish DGICYT (PB95$0110)$. A.P.M. was supported by a grant from the Danish Natural Science Research Council.

\section{References}

Andersson, M. 1982. Female choice selects for extreme tail length in a widowbird. Nature 299: 818-820.

Andersson, M. 1986. Evolution of condition-dependent sex ornaments and mating preferences: Sexual selection based on viability differences. Evolution 40: 804-816.

Andersson, S. 1992. Female preference for long tails in lekking Jackson's widowbirds: Experimental evidence. Anim. Behav. 43: $379-388$.

Andersson, M. 1994. Sexual Selection. Princeton University Press, Princeton, NJ.

Barnard, P. 1990. Male tail length, sexual display intensity and female sexual response in a parasitic African finch. Anim. Behav. 39: 652-656.

Beehler, B. \& Pruett-Jones, S. 1983. Display dispersion and the diet of birds of paradise: a comparison of nine species. Behav. Ecol. Sociobiol. 13: 229-238.

Birkhead, T.R., Atkin, L. \& Møller, A.P. 1987. Copulation behaviour in birds. Behaviour 101: 101-138.

Björklund, M. 1991. Coming of age in fringillid birds: heterochrony in the ontogeny of secondary sexual characters. J. Evol. Biol. 4: 83-92.

Bleiweiss, R., Kirsch, J.A.W. \& Matheus, J.C. 1994. DNA-DNA hybridization evidence for subfamily structure among hummingbirds. Auk 111: 8-19.

Bleiweiss, R., Kirsch, J.A.W. \& Shafi, N. 1995. Confirmation of a portion of the Sibley-Ahlquist 'tapestry'. Auk 112: 87-97.

Burns, K.J. 1998. A phylogenetic perspective on the evolution of sexual dichromatism in tanagers (Thraupidae): the role of female versus male plumage. Evolution 52: 1219-1224.

Clutton-Brock, T.H., Albon, S.D. \& Harvey, P.H. 1980. Antlers, body size and breeding group size in Cervidae. Nature 285: $565-566$.

Clutton-Brock, T.H., Harvey, P.H. \& Rudder, B. 1977. Sexual dimorphism, socioeconomic sex ratio and body weight in primates. Nature 269: 797-800.

Cronin, H. 1991. The Ant and the Peacock. Cambridge University Press, Cambridge, UK.

Darwin, C. 1871. The descent of man, and selection in relation to sex. John Murray, London, UK.

Evans, M.R. \& Hatchwell, B.J. 1992. An experimental study of male adornment in the scarlet-tufted malachite sunbird. II. The role of the elongated tail in mate choice and experimental evidence for a handicap. Behav. Ecol. Sociobiol. 29: 421-428.

Evans, M.R. \& Thomas, A.L.R. 1992. The aerodynamic and mechanical effects of elongated tails in scarlet-tufted malachite sunbirds: Measuring the cost of a handicap. Anim. Behav. 43: 337-347.

Felsenstein, J. 1985. Phylogenies and the comparative method. Am. Nat. 125: 1-15.

Fisher, R.A. 1930. The Genetical Theory of Natural Selection. Clarendon Press, Oxford, UK. 
Folstad, I. \& Karter, A.J. 1992. Parasites, bright males, and the immunocompetence handicap. Am. Nat. 139: 603-622.

Hamilton, W.D. \& Zuk, M. 1982. Heritable true fitness and bright birds: a role for parasites? Science 218: 384-387.

Harshman, J. 1994. Reweaving the tapestry: what can we learn from Sibley and Ahlquist (1990). Auk 111: 377-388.

Heywood, J.S. 1989. Sexual selection by the handicap mechanism. Evolution 43: 1387-1397.

Höglund, J. 1989. Size and plumage dimorphism in lek-breeding birds: a comparative analysis. Am. Nat. 134: 72-87.

Höglund, J. \& Sillén-Tullberg, B. 1994. Does lekking promote the evolution of male- biased size dimorphism in birds? On the use of comparative approaches. Am. Nat. 144: 881-889.

Howard, R. \& Moore, A. 1991. A Complete Checklist of the Birds of the World, 2nd edn. Academic Press, London, UK.

Irwin, R.E. 1994. The evolution of plumage dichromatism in the New World blackbirds: social selection on female brightness? Am. Nat. 144: 890-907.

Iwasa, Y., Pomiankowski, A. \& Nee, S. 1991. The evolution of costly mate preferences. II. 'Handicap' principle. Evolution 45 : 1431-1442.

Jones, I.L. \& Hunter, F.M. 1993. Mutual sexual selection in a monogamous seabird. Nature 362: 238-239.

Kirkpatrick, M., Price, T. \& Arnold, S.J. 1990. The Darwin-Fisher theory of sexual selection in monogamous birds. Evolution 44: 180-193.

Krajewski, C. 1991. Review of phylogeny and classification of birds: a study in molecular evolution. Auk 108: 987-990.

Kusmierski, R., Borgia, G., Crozier, R.H. \& Chan, B.H.Y. 1993. Molecular information on bowerbird phylogeny and the evolution of exaggerated male characteristics. J. Evol. Biol. 6: 737-752.

Lack, D. 1968. Ecological Adaptations for Breeding in Birds. Chapman \& Hall, London, UK.

Lande, R. 1981. Models of speciation by sexual selection on polygenic traits. Proc. Natl. Acad. Sci. USA 78: 3721-3725.

Livezey, B.C. 1986. A phylogenetic analysis of recent anseriform genera using morphological characters. Auk 103: 737-754.

Martin, T.E. \& Badyaev, A.V. 1996. Sexual dichromatism in birds: importance of nest predation and nest location for females versus males. Evolution 50: 2454-2460.

Mindell, D.P., ed. 1997. Avian Molecular Evolution and Systematics. Academic Press, New York, NY.

Møller, A.P. 1986. Mating systems among European passerines: a review. Ibis 128: 234-250.

Møller, A.P. 1988. Female choice selects for male sexual tail ornaments in the monogamous swallow. Nature 332: 640-642.

Møller, A.P. 1989. Viability costs of male tail ornaments in a swallow. Nature 339: 132-135.

Møller, A.P. 1992. Female swallow preference for symmetrical male sexual ornaments. Nature 357: 230-240.

Møller, A.P. 1994. Sexual Selection and the Barn Swallow. Oxford University Press, Oxford, UK.

Møller, A.P. 1998. Sexual selection. In: Sperm Competition and Sexual Selection (T. R. Birkhead \& A. P. Møller, eds), pp. 53-86. Academic Press, London, UK.

Møller, A.P. \& Birkhead, T.R. 1992. A pairwise comparative method as illustrated by copulation frequency in birds. Am. Nat. 139: 644-656.

Møller, A.P. \& Birkhead, T.R. 1994. The evolution of plumage brightness in birds is related to extrapair paternity. Evolution 48: 1089-1 100 .
Møller, A.P. \& de Lope, F. 1994. Differential costs of a secondary sexual character: an experimental test of the handicap principle. Evolution 48: 1676-1683.

Møller, A.P., de Lope, F. \& López Caballero, J.M. 1995. Foraging costs of a tail ornament: Experimental evidence from two populations of barn swallows Hirundo rustica with different degrees of sexual size dimorphism. Behav. Ecol. Sociobiology 37: 289-295.

Møller, A.P. \& Nielsen, J.T. 1997. Differential predation cost of a secondary sexual character: Sparrowhawk predation on barn swallows. Anim. Behav. 54: 1545-1551.

Møller, A.P. \& Pomiankowski, A. 1993. Why have birds got multiple sexual ornaments? Behav. Ecol. Sociobiol. 32: 167-176.

Mooers, A.Ø. \& Cotgreave, P. 1994. Sibley and Ahlquist's tapestry dusted off. Trends Ecol. Evol. 9: 458-459.

O'Hara, R.J. 1991. Review of phylogeny and classification of birds: a study in molecular evolution. Auk 108: 990-994.

Oakes, E.J. 1992. Lekking and the evolution of sexual dimorphism in birds: comparative approaches. Am. Nat. 140: 665-684.

Orians, G.H. 1969. On the evolution of mating systems in birds and mammals. Am. Nat. 103: 589-603.

Petrie, M., Halliday, T. \& Sanders, C. 1991. Peahens prefer peacocks with elaborate trains. Anim. Behav. 41: 323-331.

Pomiankowski, A., Iwasa, Y. \& Nee, S. 1991. The evolution of costly mate preferences. I. Fisher and biased mutation. Evolution 45: 1422-1430.

Raikow, R.J. 1991. Review of phylogeny and classification of birds: a study in molecular evolution. Auk 108: 985-987.

Randi, E., Fusco, G., Lorenzini, R. \& Crowe, T.M. 1991. Phylogenetic relationships and rates of allozyme evolution within the Phasianidae. Biochem. Syst. Ecol. 19: 213-221.

Saino, N., Bolzern, A.M. \& Møller, A.P. 1997a. Immunocompetence, ornamentation and viability of male barn swallows (Hirundo rustica). Proc. Natl. Acad. Sci. USA 97: 579-585.

Saino, N., Cuervo, J.J., Krivacek, M., de Lope, F. \& Møller, A.P. 1997b. Experimental manipulation of tail ornament size affects haematocrit of male barn swallows (Hirundo rustica). Oecologia 110: 186-190.

Saino, N., Cuervo, J.J., Ninni, P., de Lope, F. \& Møller, A.P. 1997c. Haematocrit correlates with tail ornament size in three populations of the barn swallow (Hirundo rustica). Funct. Ecol. 11: 604-610.

Saino, N. \& Møller, A.P. 1996. Sexual ornamentation and immunocompetence in the barn swallow. Behav. Ecol. 7: 227232.

Saino, N., Primmer, C., Ellegren, H. \& Møller, A.P. 1997d. An experimental study of paternity and tail ornamentation in the barn swallow (Hirundo rustica). Evolution 51: 562-570.

Scott, D.K. \& Clutton-Brock, T.H. 1989. Mating systems, parasites and plumage dimorphism in waterfowl. Behav. Ecol. Sociobiol. 26: 261-273.

Sheldon, F.H. \& Winkler, D.W. 1993. Intergeneric phylogenetic relationships of swallows estimated by DNA-DNA hybridization. $A u k$ 110: 798-824.

Sibley, C.G. 1994. On the phylogeny and classification of living birds. J. Avian Biol. 25: 87-92.

Sibley, C.G. \& Ahlquist, J.E. 1990. Phylogeny and Classification of Birds. Yale University Press, New Haven, CT.

Siegel, S. \& Castellan, N.J., Jr. 1988. Nonparametric Systems for the Behavioral Sciences, 2nd edn. McGraw-Hill, New York, NY. 
Smith, H.G., Montgomerie, R., Poldmaa, T., White, B.N. \& Boag, P.T. 1991. DNA fingerprinting reveals relation between tail ornaments and cuckoldry in barn swallows, Hirundo rustica. Behav. Ecol. 2: 90-97.

Sokal, R.R. \& Rohlf, F.J. 1995. Biometry, 3rd edn. Freeman, San Francisco, CA.

Temrin, H. \& Sillén-Tullberg, B. 1994. The evolution of avian mating systems: a phylogenetic analysis of male and female polygamy and length of pair bond. Biol. J. Linn. Soc. 52: 121-149.

Zahavi, A. 1975. Mate selection - a selection for a handicap. J. Theor. Biol. 53: 205-214.

Zahavi, A. 1977. The cost of honesty (further remarks on the handicap principle). J. Theor. Biol. 67: 603-605.

Received 1 March 1999; accepted 16 March 1999 


\section{Appendix}

Social mating system and ecological variables in pairs of bird species in which an extravagant feather ornament has evolved.

\begin{tabular}{|c|c|c|c|c|c|c|c|c|c|c|c|c|}
\hline & Species & $\begin{array}{l}\text { Mating } \\
\text { system }\end{array}$ & $\begin{array}{l}\text { Male nest } \\
\text { building }\end{array}$ & $\begin{array}{l}\text { Male } \\
\text { incubation }\end{array}$ & $\begin{array}{l}\text { Male food } \\
\text { provisioning }\end{array}$ & Food & $\begin{array}{l}\text { Foraging } \\
\text { mode }\end{array}$ & Sociality & $\begin{array}{l}\text { Nest } \\
\text { site }\end{array}$ & Migration & $\begin{array}{l}\text { Male } \\
\text { mass (g) }\end{array}$ & $\begin{array}{l}\text { Female } \\
\text { mass (g) }\end{array}$ \\
\hline & Podiceps cristatus & monogamous & yes & yes & yes & animal & diving & colonial & open & partial & 738 & 609 \\
\hline & Podiceps dominicus & monogamous & yes & yes & yes & animal & diving & colonial & open & resident & 129 & 116 \\
\hline & Anas falcata & monogamous & no & no & no & vegetable & swimming & solitary & open & migratory & 713 & 585 \\
\hline & Anas strepera & monogamous & no & no & no & vegetable & swimming & solitary & open & partial & 990 & 849 \\
\hline & Anas platyrhynchos & monogamous & no & no & no & vegetable & swimming & solitary & open & partial & 1170.7 & 1042.8 \\
\hline & Anas rubripes & monogamous & no & no & no & vegetable & swimming & solitary & open & partial & 1400 & 1100 \\
\hline & Aythya fuligula & monogamous & no & no & no & vegetable & diving & solitary & open & partial & 763.9 & 710.9 \\
\hline & Aythya marila & monogamous & no & no & no & vegetable & diving & solitary & open & migratory & 932 & 957 \\
\hline & Clangula hyemalis & monogamous & no & no & no & animal & diving & solitary & open & migratory & 932 & 814 \\
\hline & Melanitta nigra & monogamous & no & no & no & animal & diving & solitary & open & migratory & 1100 & 800 \\
\hline & Tetrao tetrix & lekking & no & no & no & vegetable & walking & solitary & open & resident & 1255 & 910 \\
\hline & Lagopus leucurus & monogamous & no & no & no & vegetable & walking & solitary & open & resident & 601 & 516 \\
\hline & Lophortyx californica & monogamous & no & no & yes & vegetable & walking & solitary & open & resident & 176 & 170 \\
\hline$c$ & Colinus virginianus & monogamous & yes & yes & yes & vegetable & walking & solitary & open & resident & 173 & 170 \\
\hline ¿ & Rollulus rouloul & monogamous & - & no & no & vegetable & walking & solitary & open & resident & 232 & 202 \\
\hline 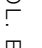 & Ptilopachus petrosus & monogamous & no & no & no & vegetable & walking & solitary & open & resident & 190 & - \\
\hline$\overline{0}$ & Gallus gallus & polygynous & no & no & no & vegetable & walking & solitary & open & resident & 877 & 556.3 \\
\hline- & Bambusicola fytchii & monogamous & - & no & no & vegetable & walking & solitary & open & resident & 319 & 278 \\
\hline ב & Phasianus colchicus & polygynous & no & no & no & vegetable & walking & solitary & open & resident & 1317 & 953 \\
\hline $\begin{array}{l}0 \\
0 \\
0 \\
0\end{array}$ & Lophura inornata & - & - & no & no & - & walking & - & open & resident & - & - \\
\hline $\begin{array}{l}0 \\
\infty \\
\infty\end{array}$ & Pavo cristatus & lekking & no & no & no & vegetable & perching & solitary & open & resident & 5000 & 3375 \\
\hline $\begin{array}{l}1 \\
1 \\
0\end{array}$ & Galloperdix spadicea & monogamous & - & no & no & vegetable & perching & solitary & open & resident & 307.1 & 326 \\
\hline $\begin{array}{l}\infty \\
\infty\end{array}$ & Otis tarda & lekking & no & no & no & vegetable & walking & solitary & open & partial & 10640 & 3962.3 \\
\hline $\overrightarrow{\overrightarrow{0}}$ & Neotis ludwigi & polygynous & no & no & no & vegetable & walking & solitary & open & resident & 4525 & 2350 \\
\hline $\begin{array}{l}0 \\
0 \\
0 \\
\Gamma\end{array}$ & $\begin{array}{l}\text { Hydrophasianus } \\
\text { chirurgus }\end{array}$ & polyandrous & yes $^{*}$ & no* & no* & animal & walking & solitary & open & partial & 126 & 231 \\
\hline 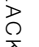 & Metopidius indicus & polyandrous & yes $^{*}$ & no* & no* & animal & walking & solitary & open & resident & 165.4 & 297.7 \\
\hline$\sum_{m}$ & Vanellus vanellus & monogamous & yes & yes & no & animal & walking & solitary & open & partial & 211 & 226 \\
\hline\ulcorner & Vanellus lugubris & monogamous & no & - & no & animal & walking & solitary & open & partial & 109.5 & 113 \\
\hline$\stackrel{\circ}{\frac{\Omega}{m}}$ & Philomachus pugnax & lekking & no & no & no & animal & walking & solitary & open & migratory & 171 & 104 \\
\hline$\sum_{0}^{m}$ & Tryngites subruficollis & lekking & no & no & no & animal & walking & solitary & open & migratory & 71 & 53 \\
\hline$\stackrel{m}{r}$ & Syrrhaptes paradoxus & monogamous & - & yes & no & vegetable & walking & colonial & open & partial & 268.2 & 239.3 \\
\hline ఠ] & Pterocles orientalis & monogamous & yes & yes & no & vegetable & walking & solitary & open & partial & 428 & 383 \\
\hline
\end{tabular}




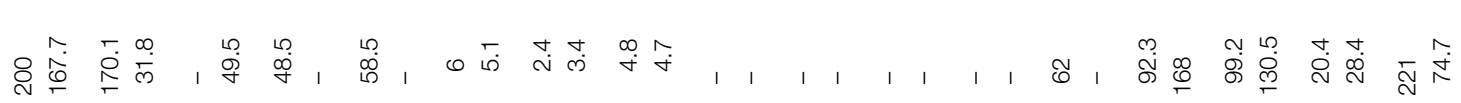

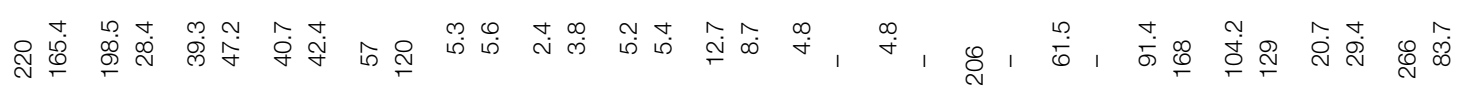

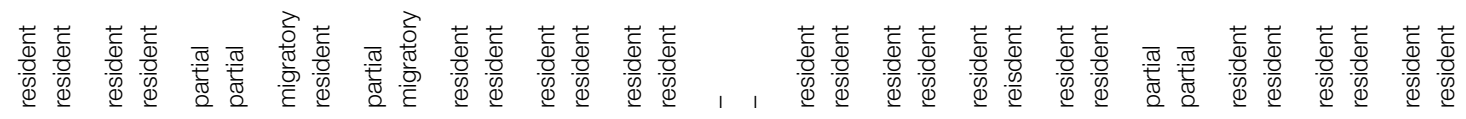

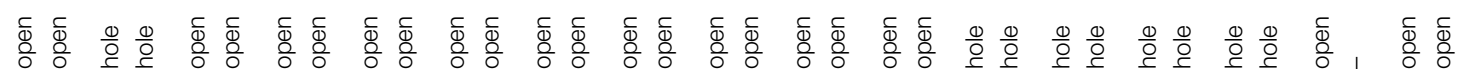

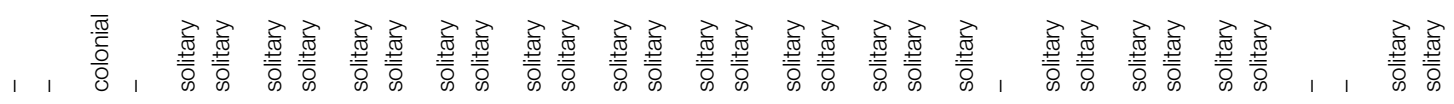

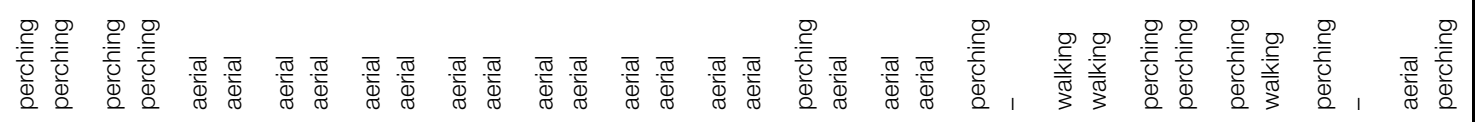

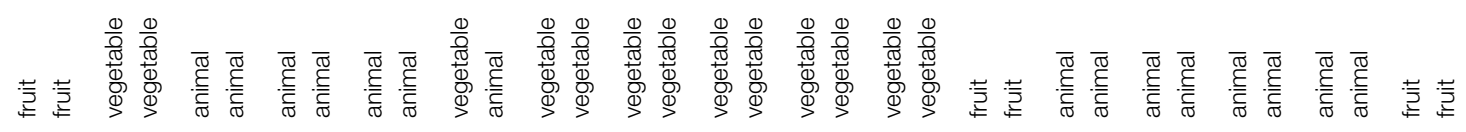

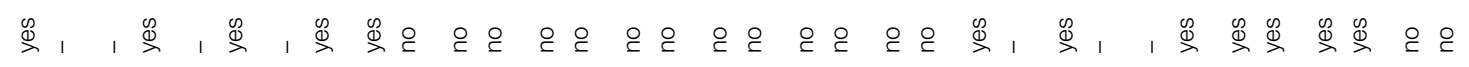

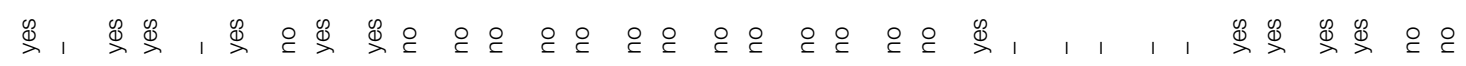

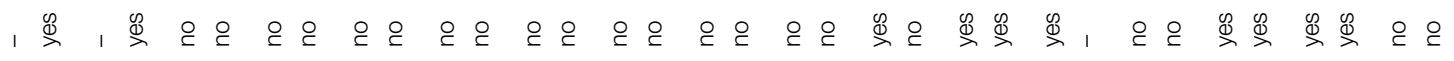

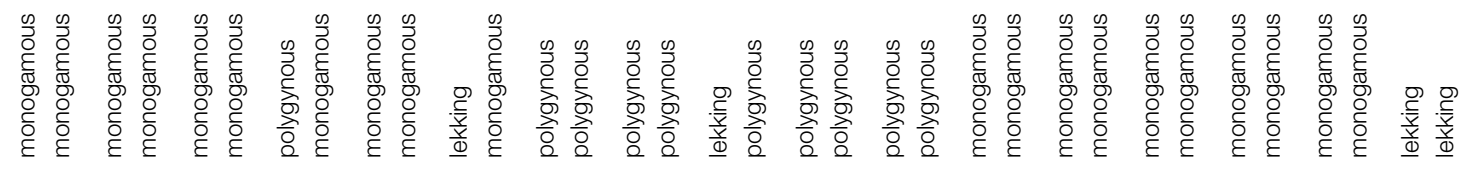

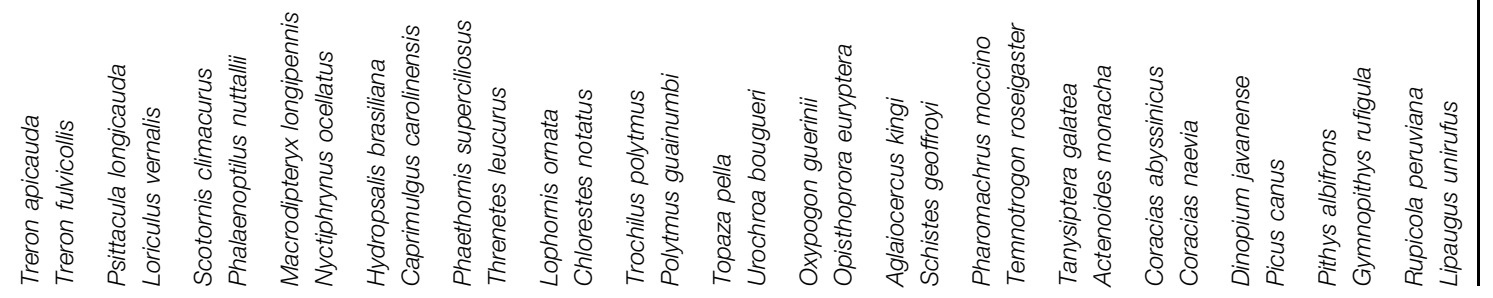


Appendix (Continued)

\begin{tabular}{|c|c|c|c|c|c|c|c|c|c|c|c|}
\hline Species & $\begin{array}{l}\text { Mating } \\
\text { system }\end{array}$ & $\begin{array}{l}\text { Male nest } \\
\text { building }\end{array}$ & $\begin{array}{l}\text { Male } \\
\text { incubation }\end{array}$ & $\begin{array}{l}\text { Male food } \\
\text { provisioning }\end{array}$ & Food & $\begin{array}{l}\text { Foraging } \\
\text { mode }\end{array}$ & Sociality & $\begin{array}{l}\text { Nest } \\
\text { site }\end{array}$ & Migration & $\begin{array}{l}\text { Male } \\
\text { mass (g) }\end{array}$ & $\begin{array}{l}\text { Female } \\
\text { mass (g) }\end{array}$ \\
\hline Pipra cornuta & lekking & no & no & no & fruit & perching & solitary & open & resident & - & - \\
\hline Pipra erythrocephala & lekking & no & no & no & fruit & perching & solitary & open & resident & 12 & 13.3 \\
\hline Chiroxiphia linearis & lekking & no & no & no & fruit & perching & solitary & open & resident & 16.8 & 19.1 \\
\hline Corapipo leucorrhoa & lekking & no & no & no & fruit & perching & solitary & open & resident & 10.9 & 13.9 \\
\hline Tyrannus savana & monogamous & yes & yes & yes & animal & aerial & solitary & open & partial & 32.8 & 29.8 \\
\hline Tyrannus tyrannus & monogamous & yes & no & yes & animal & aerial & solitary & open & migratory & 42.7 & - \\
\hline Anairetes reguloides & monogamous & yes & no & yes & animal & perching & solitary & open & resident & 5.9 & - \\
\hline Inezia subflava & monogamous & yes & no & yes & animal & perching & solitary & open & resident & 8.8 & 8.5 \\
\hline Menura novaehollandiae & lekking & no & no & no & animal & walking & solitary & open & resident & 1500 & 900 \\
\hline Atrichornis rufescens & monogamous & no & yes & yes & animal & walking & solitary & open & resident & - & - \\
\hline Eremophila alpestris & monogamous & no & no & yes & vegetable & walking & solitary & open & partial & 31.9 & 30.8 \\
\hline Eremopterix australis & monogamous & no & yes & yes & vegetable & walking & solitary & open & resident & 14 & 15 \\
\hline Hirundo semirufa & monogamous & yes & no & - & animal & aerial & solitary & open & partial & 25.5 & 21.3 \\
\hline Hirundo preussi & monogamous & yes & - & - & animal & aerial & colonial & hole & partial & 12.2 & 14 \\
\hline Hirundo rustica & monogamous & yes & no & yes & animal & aerial & colonial & open & migratory & 18.7 & 18.5 \\
\hline Hirundo rufigula & monogamous & - & yes & yes & animal & aerial & colonial & hole & partial & - & - \\
\hline Psalidoprocne obscura & monogamous & yes & - & - & animal & aerial & colonial & hole & partial & 9.4 & 10 \\
\hline Psalidoprocne nitens & monogamous & yes & - & - & animal & aerial & solitary & hole & resident & 9.5 & 10 \\
\hline Dryoscopus sabini & - & - & - & - & - & - & - & - & - & 39.9 & 36.9 \\
\hline Tchagra minuta & monogamous & yes & yes & - & animal & perching & solitary & open & partial & 33 & 34.7 \\
\hline Ptilogonys caudatus & monogamous & yes & no & yes & fruit & aerial & solitary & open & resident & 39.1 & 33.5 \\
\hline Hypocolius ampelinus & monogamous & yes & yes & yes & fruit & aerial & colonial & open & migratory & 54 & 52.8 \\
\hline Phainopepla nitens & monogamous & yes & yes & yes & fruit & perching & solitary & open & partial & 24 & - \\
\hline Phainoptila melanoxantha & monogamous & - & - & - & fruit & perching & solitary & open & resident & 56 & - \\
\hline Copsychus malabaricus & monogamous & no & no & yes & animal & walking & solitary & hole & resident & 32 & 31 \\
\hline Copsychus saularis & monogamous & no & no & yes & animal & walking & solitary & hole & resident & 37.9 & 34.5 \\
\hline Panurus biarmicus & monogamous & yes & yes & yes & vegetable & perching & colonial & open & resident & 15.6 & 14.9 \\
\hline Paradoxornis gularis & - & - & - & - & vegetable & perching & - & open & resident & 29 & 29 \\
\hline Orthotomus sutorius & monogamous & yes & yes & yes & animal & perching & solitary & open & resident & 8.7 & 7.8 \\
\hline Orthotomus atrogularis & monogamous & - & yes & - & animal & perching & solitary & open & resident & 8.1 & 7.3 \\
\hline Malurus splendens & monogamous & no & no & yes & animal & walking & solitary & open & resident & 9.5 & 8.5 \\
\hline Malurus coronatus & monogamous & no & no & yes & animal & walking & solitary & open & resident & 10.5 & 10 \\
\hline Terpsiphone viridis & monogamous & - & yes & yes & animal & aerial & solitary & open & resident & 15.1 & 14.6 \\
\hline Chasiempis sandwichensis & monogamous & yes & yes & yes & animal & aerial & solitary & open & resident & 14 & - \\
\hline
\end{tabular}




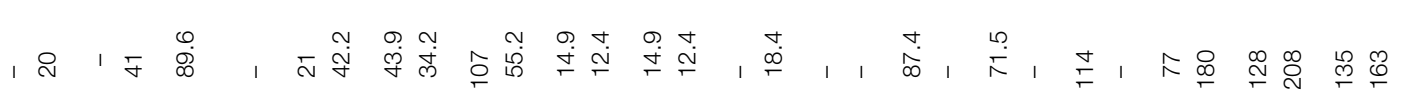

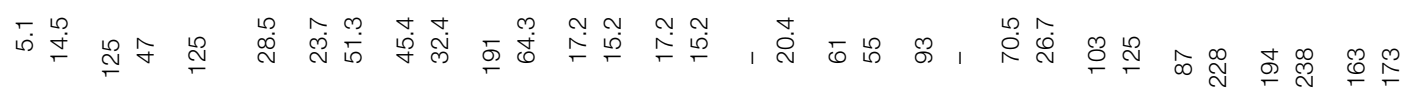

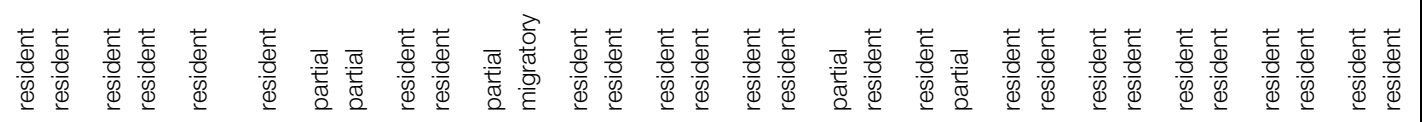

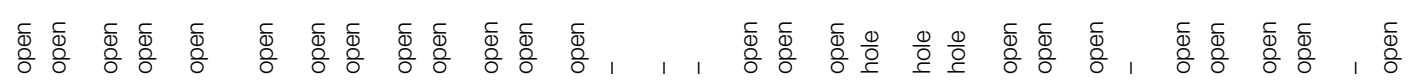

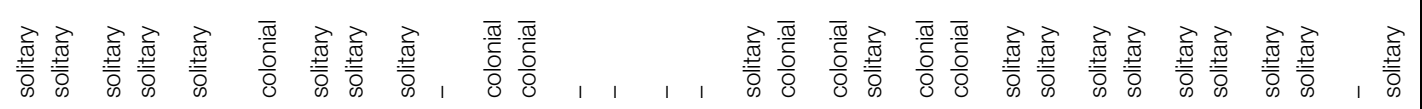

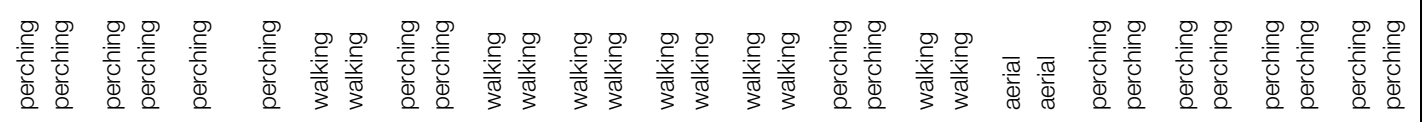

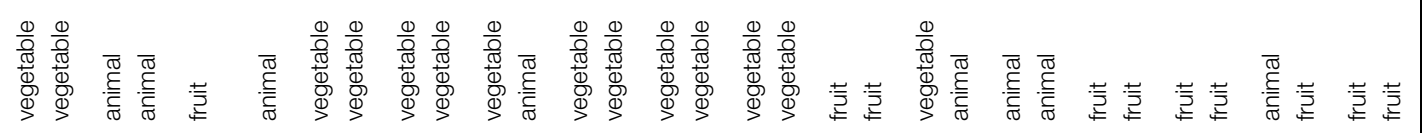

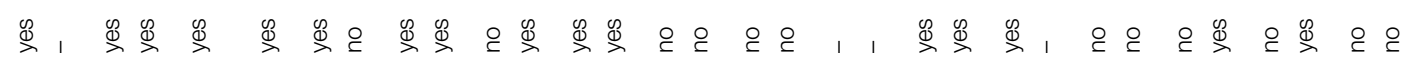

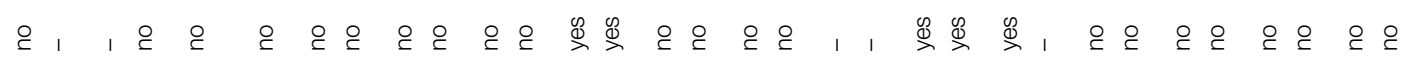

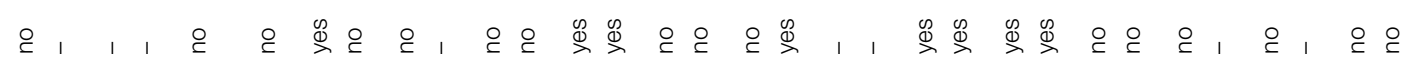

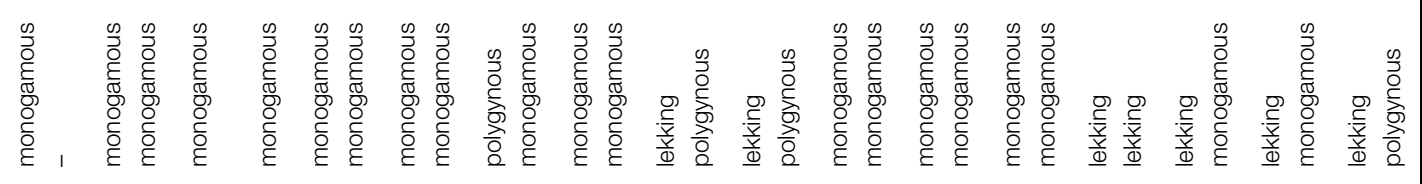

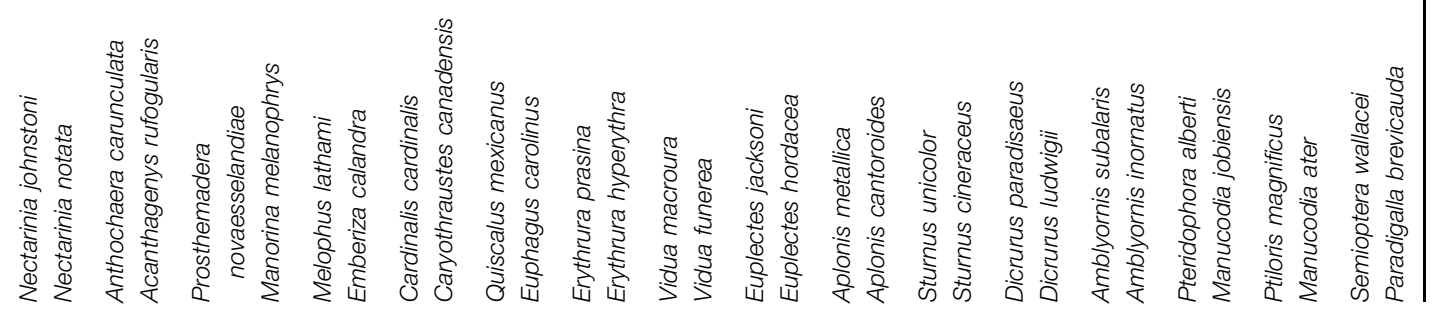


Appendix (Continued)

\begin{tabular}{|c|c|c|c|c|c|c|c|c|c|c|c|}
\hline Species & $\begin{array}{l}\text { Mating } \\
\text { system }\end{array}$ & $\begin{array}{l}\text { Male nest } \\
\text { building }\end{array}$ & $\begin{array}{l}\text { Male } \\
\text { incubation }\end{array}$ & $\begin{array}{l}\text { Male food } \\
\text { provisioning }\end{array}$ & Food & $\begin{array}{l}\text { Foraging } \\
\text { mode }\end{array}$ & Sociality & $\begin{array}{l}\text { Nest } \\
\text { site }\end{array}$ & Migration & $\begin{array}{l}\text { Male } \\
\text { mass (g) }\end{array}$ & $\begin{array}{l}\text { Female } \\
\text { mass (g) }\end{array}$ \\
\hline Lophorina superba & lekking & no & no & no & fruit & perching & - & open & resident & 87 & 67 \\
\hline Macgregoria pulchra & monogamous & no & no & yes & fruit & perching & solitary & open & resident & 279 & 206 \\
\hline Parotia lawesii & lekking & no & no & no & fruit & perching & solitary & open & resident & 167 & 144 \\
\hline Loboparadisea sericea & - & - & - & - & fruit & perching & - & open & resident & 64 & 73 \\
\hline Diphyllodes magnificus & lekking & no & no & no & fruit & perching & solitary & open & resident & 97 & 82 \\
\hline Loria loriae & polygynous & no & no & no & fruit & perching & - & open & resident & 85 & 81 \\
\hline Paradisaea rubra & lekking & no & no & no & fruit & perching & solitary & open & resident & 201 & 158 \\
\hline Lycocorax pyrrhopterus & monogamous & - & - & - & fruit & perching & - & open & resident & 302 & 266 \\
\hline
\end{tabular}

The first species listed for each pair is the ornamented species and the second is the nonornamented species. For detalied explanation or variables, see Methods. The sources of information concerning the ecological variables will be provided to the readers upon request. *Female parental care. 